\title{
AMAR
}

AMAR (Andalas Management Review)

Vol. 2, No. 2 (2018) 28-41

The Management Institute, Faculty of Economics, Universitas Andalas

ISSN (Print) 2476-9282 | ISSN (Online) 2548-155X

\section{Analisis Pengaruh Spiritual Leadership terhadap Komitmen Organisasional Karyawan}

\author{
Nia Ariyani Erlin ${ }^{a}$, Herri $^{b}$ \\ a,bDepartemen Manajemen Universitas Andalas, niaariyanierlin@gmail.com
}

\begin{abstract}
The research aimed to determinie how much influence of Transformasional Leadership Style, Works Discipline and Compensation on teacher performance at SMK Global Mulia Bekasi partially and simultaneously. Sampling in this Research is done by using satuarated sampling technique. The sample used was 30 respondents from the population of 30 teachers. The data were collected by using questionnaires. The method used in this research is quantitative method. While The data analysis technique used is multiple linear regression analysis with the use of SPSS program version 24. The results showed that the three independent variables of transformational leadership style, work discipline and Compensation together partially or simultaneously have a positive and significant effect on Teacher Performance. Compensation is the biggest significant variabel in influencing the performance of SMK Global Mulia Bekasi Teachers.
\end{abstract}

Keyword: Transformasional Leadership Style, Works Discipline, Compensation, Teacher Performance

\section{PENDAHULUAN}

Dunia bisnis saat ini semakin kompleks dan dinamis karena selalu dituntut untuk memenuhi kebutuhan dan keinginan manusia yang tidak terbatas. Bahkan, tuntutan peningkatan kinerja keuangan perusahaan kadangkala membuat perusahaan melakukan praktik yang tidak mengikuti aturan etika dan moral yang berlaku. Sebagai contoh, kasuskasus yang terjadi pada perusahaan besar Amerika seperti; Enron, Worldcom, dan Global Crossing yang terkenal dengan strategi, manajemen, dan regulasinya ternyata tidak mampu menyelaraskannya dengan konsep-konsep yang menjadi isu saat ini, yaitu etika dan moral (Kartajaya dan Sula, 2006). Pelanggaran-pelanggaran konsep etika dan moral saat ini dikarenakan perusahaan hanya fokus pada laba jangka pendek perusahaan, tanpa memperhatikan bagaimana kehidupan perusahaan di masa depan. Padahal, aktivitas perusahaan yang hanya berfokus pada kinerja keuangan pada hakikatnya telah meletakkan perusahaan di jurang resiko jangka panjang. 
Hal ini kemudian dijelaskan oleh Kaplan dan Norton (2004) bahwa kinerja perusahaan masa kini tidak hanya dapat diwakilkan dari matriks-matriks keuangan. Kaplan dan Norton menciptakan suatu alat perencanaan strategis yang disebut Balance Scorecard. Ada empat perspektif dalam organisasi balance scorecard; perspektif keuangan, perspektif pelanggan, perspektif bisnis internal, perspektif pemberdayaan dan pertumbuhan. Fry (2005) menyebutkan perkembangan terbaru dari Strategic Scorecard lebih fokus pada indikator kesejahteraan, komitmen, dan produktivitas karyawan yang dapat mempengaruhi kinerja strategis. Teori spiritual leadership menurut Fry \& Matherly (2007) dapat membantu mewujudkan perspektif pemberdayaan dan pertumbuhan di Balance Scorecard bagian sumber daya manusia.

Spiritual leadership merupakan salah satu bentuk pengembangan teori kepemimpinan berbasis motivasi yang muncul untuk menawarkan solusi atas permasalahan-permasalahan terkait kepemimpinan saat ini. Spiritual leadership dianggap sebagai cara efektif untuk memimpin di era pasca-revolusi industri saat ini yang sangat membutuhkan transformasi organisasi. Organisasi yang dulu bersifat transaksional, sentralisasi, standardisasi, dan formalisasi harus ditransformasikan kepada organisasi pembelajar. Fry, Vitucci, \& Cedillo (2005) menyatakan bahwa spiritual leadership dapat meningkatkan komitmen organisasional karyawan. Namun hasil studi empiris yang dilakukan menunjukkan perolehan nilai yang rendah untuk nilai komitmen organisasional. Oleh karena itu, penulis mereplikasi penelitian Fry dkk., (2005) yang berjudul "Spiritual leadership and army transformation: Theory, measurement, and establishing a baseline", untuk dapat mendukung teori atau hasil studi empiris yang telah diteliti sebelumnya.

Ada beberapa perbedaan penelitian ini dengan Fry dkk. (2005). Penelitian Fry dkk. (2005) adalah penelitian longitudinal, sedangkan penelitian ini adalah penelitian cross sectional dengan asumsi Toko Sari Anggrek adalah toko yang sudah dipimpin oleh seorang spiritual leader. Ini dapat dilihat dari nilai-nilai spiritual leadership yang dimiliki oleh pimpinan toko dan upaya-upaya yang dilakukan untuk membentuk kongruensi nilai untuk menanamkan nilai transendensi kepada setiap karyawan yang didefinisikan dalam kegiatan kajian keislaman yang dilakukan setiap pekan. Pelestarian nilai transendensi dilakukan dengan adanya fasilitasi shalat di tempat yang nyaman, adzan langsung oleh salah satu karyawan diikuti shalat berjamaah, pakaian menutup aurat, dan istirahat toko selama waktu shalat jum'at. Selain itu, sampel penelitian Fry dkk. (2005) adalah organisasi yang memiliki desain mekanistik, yaitu angkatan militer, sedangkan penelitian ini akan mencoba menganalisis penerapan konsep spiritual leadership dari sisi organisasi berdesain organik, yaitu sebuah 
toko. Penelitian ini ingin membuktikan apakah penerapan spiritual leadership pada organisasi berdesain organik dapat menguatkan komitmen organisasional karyawan, dimana pada penelitian Fry dkk. (2005) ditemukan bahwa komitmen organisasional angkatan militer dikonfirmasi rendah.

\subsection{Konsep Komitmen organisasional}

Penelitian-penelitian membuktikan bahwa komitmen berpengaruh positif terhadap beberapa outcome organisasi. Misalnya, karyawan yang berkomitmen pada organisasinya terbukti memiliki perilaku negatif seperti absen dan berhenti yang rendah, sementara itu memiliki perilaku positif seperti perlaku kewarganegaraan terhadap organisasi yang tinggi (Markow dan Klenke, 2005). Inkai dan Kistyanto (2013) mendefinisikan komitmen organisasional sebagai sebuah kepercayaan karyawan pada organisasi dan penerimaan terhadap tujuan-tujuan dan nilai-nilai organisasi, serta ketertarikan untuk tetap menjadi bagian dari organisasi dan berkaitan erat dengan niat atau intensi tetap bertahan atau loyal terhadap organisasi.

Meyer dan Allen (1991) mengonsepkan bahwa komitmen terbagi menjadi tiga komponen, komitmen afektif (sebuah keinginan), normatif (sebuah kewajiban) dan berkelanjutan (sebuah kebutuhan). Komitmen afektif adalah keterikatan emosi seseorang terhadap organisasinya. Penelitian ini hanya akan fokus menguji pengaruh spiritual leadership terhadap komitmen afektif individu di organisasinya. Hal ini disebabkan komitmen afektif berkaitan dengan keterikatan emosional dan psikologis seseorang kepada organisasi, maka akan tepat bila dihubungkan dengan konsep spiritual leadership yang berkaitan dengan dimensi-dimensi di tataran psikologis individu.

\subsection{Konsep Spiritual Leadership}

Ada beberapa teori yang dikemukakan oleh beberapa pakar tentang spiritual leadership. Pertama adalah Fairholm (1996) yang mengajukan beberapa dimensi spiritual dalam kepemimpinan. Dimensi-dimensi tersebut adalah morality, stewardship dan community . Dari sisi moral diantaranya membangun visi yang bernilai, selalu berusaha melakukan perubahan yang lebih baik. Stewardship diantaranya dengan menata pelayanan yang ditunjang oleh pemberdayaan dan kemitraan. Kemudian community yaitu menciptakan komunitas yang terjalin erat dan bertujuan untuk pengembangan anggota kelompok.

Selanjutnya spiritual leadership yang digagas oleh Tobroni yang sudah memasukan unsur religi atau agama di dalam konsepnya. Hal ini dikarenakan kepemimpinan spiritual 
mengembangkan tiga pilar penyangga keefektifan kepemimpinannya: (1) mengembangkan kekuatan individu positif (2) mengembangkan kekuatan penggerak dan perekat organisasi positif dan (3) mengembangkan kekuatan nilai-nilai budaya positif (Tobroni, 2010).

Penelitian ini akan fokus kepada Teori spiritual leadership yang dikemukakan oleh Louis W. Fry. Fry mengemukakan teori spiritual leadership yang lebih jelas hubungan antar dimensinya. Tujuan penerapan Spiritual leadership menurut Fry adalah untuk membantu oraganisasi-organisasi bertransformasi menjadi organisasi pembelajar agar dapat bertahan di era ekonomi abad ini. Fry (2005) mendefinisikan spiritual leadership sebagai sebuah nilai, sikap dan perilaku pemimpin strategis yang diperlukan dalam upaya memotivasi diri sendiri maupun orang lain melalui calling dan membership, sehingga terbentuk perasaan sejahtera secara spiritual. Nilai, sikap, dan perilaku yang dimiliki pemimpin dikelompokkan kepada tiga dimensi yang akan memiliki kaitan dalam aktivitasnya. Dimensi-dimensi tersebut adalah altruisme (altruistic love), harapan/keyakinan (hope/faith), dan visi (vision). Hubungan pengaruh ketiga dimensi ini menurut Fry (2003) adalah seperti skema berikut:

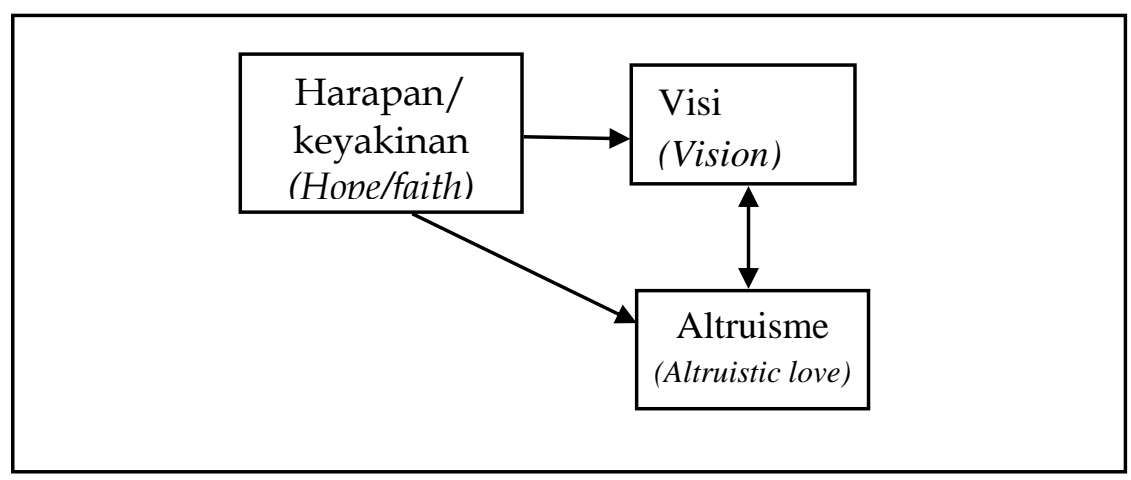

Gambar 1: Dimensi-dimensi spiritual leadership dan hubungannya Sumber: Fry (2003)

Ketiga dimensi yang membangun konstruk spiritual leadership ini berasal dari inner life (Fry, 2003). Sumber spiritual leadership adalah inner life atau praktik spiritual yang secara fundamental merupakan sumber inspirasi dan insight, secara positif mempengaruhi perkembangan (1) harapan/keyakinan pada visi transendensi dari pelayanan terhadap pemegang kepentingan kunci dan (2) nilai-nilai altruisme (Fry dan Cohen, 2009). Koneksi antara spiritualitas dan kepemimpinan adalah kesadaran yang dimiliki oleh 'inner voice' yang merupakan sumber utama dari setiap kebijaksanaan atas masalah-masalah terberat dan keputusan-keputusan personal seseorang (Levy, 2000).

Altruisme dalam kontekstual teori ini, merupakan sebuah rasa keutuhan, harmoni, dan akan menjadi lebih produktif melalui perhatian, belas kasih, dan adanya penghargaan/ 
apresiasi baik pada diri maupun orang lain (Asmaningrum, 2009). Penghubung yang umum antara spiritualitas dan religi adalah nilai altruisme, yaitu penghargaan atau kesetiaan terhadap ketertarikan dengan orang lain (Fry, 2008). Seorang spiritual leader memiliki nilainilai altruisme dalam dirinya. Visi dalam kontekstual spiritual leadership ini menunjukkan adanya tampilan kinerja (performance) yang ingin dicapai oleh seluruh anggota organisasi. (Asmaningrum, 2009). Seorang pemimipin yang menciptakan visi yang dilandasi dengan nilai-nilai altruisme yang positif akan menghasilkan visi yang positif sehingga cara yang dapat dilakukan pemimpin untuk dapat merealisasikan visi adalah menciptakan pemahaman dan nilai-nilai yang sama pada karyawannya.

Hipotesis 1 : Altruisme (altruistic love) secara signifikan dan positif berpengaruh terhadap visi seseorang.

Nilai altruisme yang dimiliki pemimpin akan mempengaruhi penciptaan dan pewujudan visi disamping itu juga akan menumbuhkan harapan dan keyakinan dalam hidup individu. Harapan dan kepercayaan pada organisasi akan menjaga dan mempertahankan pengikut untuk berpandangan kedepan serta memberikan keinginan dan cita-cita positif yang memberi energi dari usaha melalui motivasi intrinsik.

Hipotesis 2: Altruisme (altruistic love/ reward) secara signifikan dan positif berpengaruh terhadap harapan/keyakinan (hope/faith) seseorang.

Harapan dan keyakinan yang ada pada diri pemimpin akan menumbuhkan kepercayaan dan motivasi yang kuat bahwa visi yang dirancang akan dapat diwujudkan.

Hipotesis 3: Harapan/keyakinan (hope/faith) secara signifikan dan positif berpengaruh terhadap visi.

\subsection{Mekanisme Spiritual Leadership}

Hasil penelitian yang dilakukan oleh Fry dan Cohen (2009), menjelaskan bahwa Spiritual Leadership akan membantu mengembangkan nilai kemanusiaan yang positif. Selian itu, ia juga dapat mengembangkan psikologis dan keadaan spiritual yang bermuara pada tercapainya komitmen organisasi, produktivitas dan kinerja organisasi melalui dimensi-dimensinya; altruisme, visi, harapan/keyakinan, mampu meningkatkan komitmen organisasional karyawan melalui calling yaitu rasa keterpanggilan (karena memahami arti atau hakikat pekerjaan) dan membership (rasa keanggotaan). 


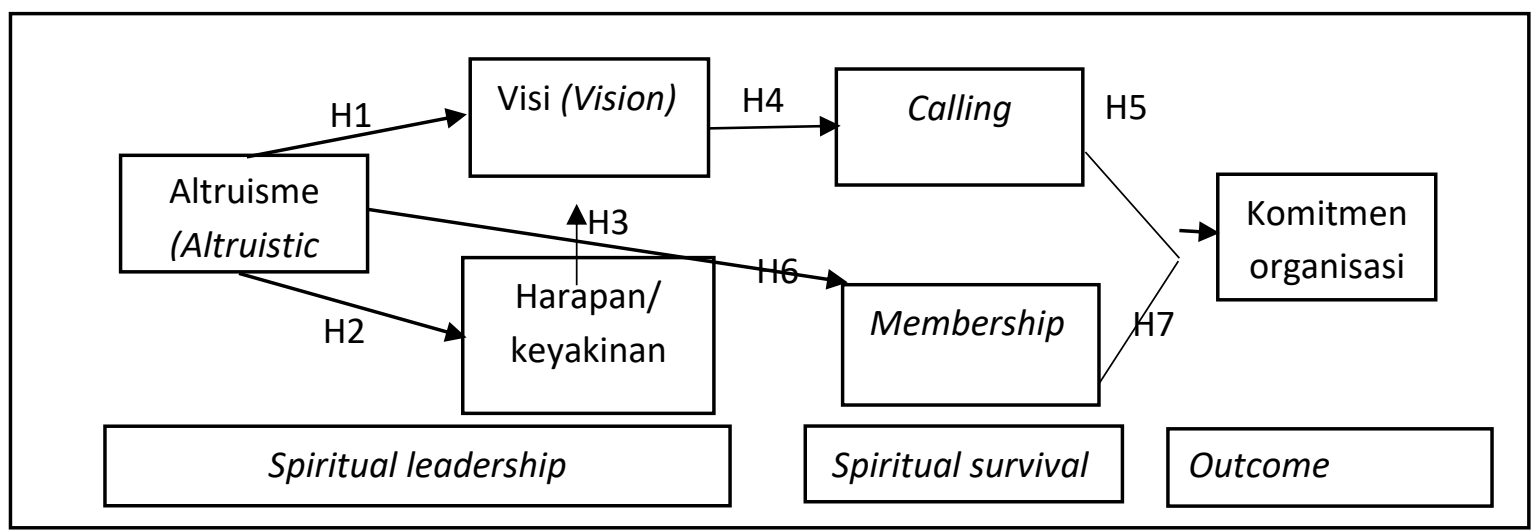

Gambar 2: Dimensi-dimensi spiritual leadership mekanisme kerja spiritual leadership

Kongruensi nilai yang sama antara pemimpin dan karyawan dapat diciptakan oleh seorang spiritual leader dengan menanamkan visi yang berasal dari nilai-nilai transendensi kepada karyawan. Karyawan akan memahami hakikat pekerjaannya dan akhirnya menumbuhkan rasa terpanggil dalam bekerja (calling) kemudian akan termotivasi secara intrinsik. Calling adalah sebuah perasaan bahwa hidup seseorang itu memiliki makna dan membuat kehidupan menjadi berbeda (Fry, 2008). Penelitian oleh Markow dan Klenke (2005) menjelaskan bahwa "personal meaning" yang muncul dari rasa transendensi terbukti sebagai prediktor signifikan untuk calling.

Hipotesis 4: Visi berpengaruh signifikan dan positif terhadap Calling.

Motivasi secara intrinsik dari dalam diri sendiri karena merasa terpanggil dan memahami hakikat pekerjaan akan menciptakan komitmen yang lebih tinggi di diri karyawan terhadap pekerjaannya. Penelitian oleh Markow dan Klenke (2005) membuktikan bahwa makna pribadi (personal meaning) terkait pada rasa keterpanggilan yang akan memediasi komitmen terhadap organisasinya. Ini berarti calling menjadi prediktor yang signifikan dari komitmen organisasional individu.

Hipotesis 5: Calling berpengaruh signifikan dan positif terhadap komitmen organisasional karyawan.

Membership merupakan sebuah rasa bahwa karyawan dimengerti, dipahami dan dihargai (Fry, 2008). Sedangkan altruisme merupakan sebuah rasa keutuhan, harmoni, dan akan menjadi lebih produktif melalui perhatian, belas kasih, dan adanya penghargaan/ apresiasi baik pada diri maupun orang lain (Asmaningrum, 2009). Aktivitas-aktivitas spiritual leader dengan karyawannya yang dilandasi nilai altruisme akan menciptakan rasa keanggotaan yang kuat pada karyawan karena nilai altruisme yang dimiliki pimpinan membuat karyawan merasa dipercaya dan dihargai dalam berinteraksi. Dengan demikian, 
perasaan membership yang kuat akan meningkatkan komitmen karyawan terhadap organisasinya.

Hipotesis 6: Altruisme berpengaruh signifikan dan positif terhadap membership.

Hipotesis 7: Membership berpengaruh signifikan positif terhadap komitmen organisasional karyawan.

\section{METODE}

Penelitian ini adalah penelitian kuantitatif dengan pendekatan pengujian hipotesis atau hypothesis testing yang bertujuan untuk menguji pengaruh masing-masing dimensi spiritual leadership terhadap komitmen organisasional karyawan. Sampel penelitian adalah seluruh karyawan toko Sari Anggrek, Padang, dengan kata lain metode pengambilan sampel adalah dengan menggunakan total sampling atau survei. Ini dimaksudkan untuk dapat memperoleh informasi secara utuh tentang bagaimana persepsi karyawan terhadap spiritual leadership pemimpinnya.

Sumber utama data adalah sumber primer yang didapatkan langsung dari responden yang mengisi kuesioner, sebanyak 60 responden. Selain itu, kajian-kajian kepustakaan sebagai sumber sekunder juga diambil. Data dianalisis dengan menggunakan metode SEM. Ini didasari karena kelebihan-kelebihan SEM dan kecocokannya dengan penelitian. Model penelitian ini mengandung variabel yang berhubungan ganda. Ada variabel dependen yang juga menjadi independen bagi variabel lain. Seperti variabel calling yang menjadi variabel dependen dari variabel visi, namun menjadi variabel independen unuk komitmen organisasional.

Diantara aplikasi analisis data SEM, penulis memilih menggunakan PLS karena sampel yang dimiliki terbatas, yaitu 60 sampel. Sejauh pemahaman penulis. hanya PLS yang mendukung pengolahan data dengan sampel dibawah 100 responden. Selain PLS, aplikasi SEM lainnya seperti AMOS dan Lisrel mensyaratkan jumlah sampel besar untuk dapat dianalisis. Kuesioner yang digunakan dalam penelitian ini adalah kuesioner yang telah dirancang dan digunakan oleh Fry, dkk. (2005) untuk variabel-variabel spiritual leadership dan spiritual survival. Modifikasi juga dilakukan pada beberapa pertanyaan sesuai pemahaman calon responden. Modifikasi dilakukan dengan menambahkan beberapa kata, frasa, dan menyesuaikan pola kalimat yang cocok dengan tingkat pemahaman karyawan Toko. Selain itu, dilakukan pengembangan pernyataan untuk variabel altruisme karena dalam satu pertanyaan bisa saja ada tanggapan yang berbeda karena ada dua sikap yang mungkin bisa 
ditanggapi berbeda. Variabel komitmen organisasional (afektif) dalam penelitian ini menggunakan pengukuran yang dikembangkan oleh Allen dan Meyer (1990).

\section{HASIL DAN PEMBAHASAN}

Hasil uji hipotesis menunjukkan bahwa spiritual leadership dapat meningkatkan komitmen organisasional karayawan dengan diperolehnya nilai yang memenuhi signifikansi diterimanya hipotesis. Altruisme berpengaruh signifikan terhadap visi dengan nilainya yang lebih besar dari 1,96, yaitu 16,000. Hipotesis kedua yang menguji pengaruh altruisme terhadap harapan/keyakinian juga menghasilkan nilai signifikan yaitu 11,216 yang lebih besar dari 1,96. selanjutnya pengaruh harapan/keyakinan terhadap ketercapaian visi juga memiliki nilai yang signifikan dan positif, yaitu sebesar 2,1. Hipotesis keempat tentang visi seorang pemimpin akan mendorongnya menciptakan calling pada dirinya dan memotivasi secara intrinsik karyawannya sehingga memiliki kongruensi nilai mencapai tujuan juga memiliki nilai signifikan, yaitu 4,966.

Tabel 1

Hasil Uji Hipotesis

\begin{tabular}{|c|c|c|c|c|c|}
\hline & $\begin{array}{c}\text { Original } \\
\text { Sample } \\
\text { (O) }\end{array}$ & $\begin{array}{c}\text { Sample } \\
\text { Mean (M) }\end{array}$ & $\begin{array}{c}\text { Standard } \\
\text { Deviation } \\
\text { (STDEV) }\end{array}$ & $\begin{array}{c}\text { T Statistics } \\
(|\mathrm{O} / \mathrm{STDEV}|)\end{array}$ & P Values \\
\hline $\begin{array}{l}\text { Altruisme -> Harapan/ } \\
\text { Keyakinan }\end{array}$ & 0.680 & 0.693 & 0.061 & 11.216 & 0.000 \\
\hline Altruisme -> Membership & 0.550 & 0.558 & 0.126 & 4.377 & 0.000 \\
\hline Altruisme -> Visi & 0.756 & 0.763 & 0.047 & 16.000 & 0.000 \\
\hline Calling -> Komitmen & 0.232 & 0.233 & 0.090 & 2.591 & 0.010 \\
\hline $\begin{array}{l}\text { Harapan/Keyakinan -> } \\
\text { Visi }\end{array}$ & 0.317 & 0.318 & 0.151 & 2.100 & 0.036 \\
\hline Membership -> Komitmen & 0.694 & 0.700 & 0.067 & 10.388 & 0.000 \\
\hline Visi -> Calling & 0.546 & 0.549 & 0.110 & 4.966 & 0.000 \\
\hline
\end{tabular}

Sumber: Output SmartPLS 3.2.4 (2016)

Begitu pula dengan variabel lain dari spiritual survival, yaitu membership, yang dipengaruhi oleh altruisme dimana nilai pengaruhnya juga signifikan, yaitu 4,377. Hipotesis 5 dan 7 mengenai calling dan membership yang berpengaruh terhadap komitmen organisasional juga memiliki nilai yang signifikan dan positif. Nilai tersebut berturut-turut adalah 2,591 dan 10,388 yang keduanya lebih besar dari 1,96. variabel-variabel yang saling terangkai dari model penelitian berdasarkan pengaruhnya ini telah terbukti saling berhubungan positif sehingga mampu meningkatkan komitmen organisasional karyawan. 
Table 1 diatas adalah tabel Total Effect yang memaparkan hasil pengujian hipotesis melalui program Bootstraping pada PLS3.2.4.

\subsection{Pengaruh Altruisme terhadap Visi}

Nilai-nilai kebaikan yang merupakan nilai-nilai altruisme yang dimiliki pimpinan akan mempengaruhi penciptaan visi dan cara pencapaian visi seseorang. Nilai-nilai altruisme yang dimiliki pimpinan toko sari anggrek mempengaruhi pelaksanan visi toko, yaitu mencerdaskan kehidupan rakyat, menyebarkan ilmu, dan mengurangi pengangguran (berdasarkan hasil wawancara bersama pemimpin). Fry (2003) menjelaskan, visi dalam spiritual leadership dibagi menjadi lima uraian, yaitu: kedekatan yang kuat dengan stakeholder kunci, mendefinisikan tujuan dan jalannya, idealisme yang tinggi, mendukung keyakinan, dan membangun standar yang baik.

Ketika dipahami lebih lanjut, visi ini sangat berhubungan dengan salah satu stakeholder kunci, yaitu konsumen. Visi toko ini jelas dan mudah dipahami sehingga jalan pewujudannya juga realistis dan sesuai standar toko untuk dilaksanakan. Mencerdaskan kehidupan rakyat dan menyebarkan ilmu adalah bentuk idealisme yang tinggi. Selain itu, dalam aktivitasnya mengelola toko, pimpinan yang memiliki nilai altruisme akan mengatur jalannya aktivitas toko dengan cara-cara yang didasari oleh sikap altruisme yang dimiliki.

Hasil ini memberikan impikasi kepada para pemimpin bahwa nilai-nilai altruisme yang dimiliki pemimpin akan mempengaruhi pembentukan visi perusahaan. Jika perusahaan sudah mempunyai visi, maka nilai altruime akan mempengaruhi pewujudan visi tersebut.

\subsection{Pengaruh Altruisme terhadap Harapan/Keyakinan}

Nilai-nilai altruisme sangat dekat dengan nilai-nilai harapan/keyakinan karena keduanya dibentuk dari nilai-nilai dan sikap-sikap positif. Bahkan Fry (2003) menggabungkan nilai-nilai pembentuk altruisme dengan nilai-nilai hope/faith menjadi 11 butir karena keduanya mampu menghilangkan nilai-nilai negatif yang mungkin dimiliki seseorang. Pada penelitian ini, altruisme terbukti berpengaruh signifikan terhadap harapan/keyakinan seseorang.

\subsection{Pengaruh Harapan/Keyakinan terhadap Visi}

Penelitian ini membuktikan bahwa Harapan/Keyakinan berpengaruh positif terhadap visi. Saat diwawancarai mengenai beberapa aktivitas berbeda yang dilakukan toko Sari Anggrek, seperti kajian pekanan, adzan setiap waktu shalat, toko tutup saat shalat jum'at, 
berbuka bersama setiap hari di bulan ramadhan, fasilitasi english club, pimpinan toko menyebutkan tujuannya hanya ridha Tuhan. Ini menunjukkan, harapan/keyakinan dalam hati pemimpin akan menguatkannya untuk merealisasikan program-program tertentu agar dapat mencapi visi. Selain itu, keyakinan tersebut juga mengajarkan sikap tabah, tekun, bekerja sesuai tugas, fokus pada tujuan, dan optimis sukses akan mencapai visinya: mendapatkan ridha Tuhan.

\subsection{Pengaruh Visi terhadap Calling}

Penelitian ini membuktikan bahwa visi berpengaruh signifikan pada calling. Pengaruh ini dapat dijelaskan berdasar hasil wawancara dengan pimpinan Sari Anggrek yang menjelaskan bahwa tujuan pimpinan Sari Anggrek untuk mencapai ridha Tuhan. Hal ini menjadikan pimpinan memahami hakikat kerjanya sehingga aktivitas bekerja adalah sebuah panggilan untuknya. Rasa terpanggil karena mengetahui arti dan hakikat pekerjaan adalah sebuah bentuk transendensi seseorang. Transendensi adalah perasaan dimana seseorang menyadari bahwa ada sesuatu yang lebih kuasa daripada dirinya sendiri. Nilai-nilai spiritual leadership, calling, dan transendensi inilah yang ingin diwujudkan secara kongruen dengan karyawan. Ketika pimpinan dan pengikut sudah memiliki kesamaan nilai (kongruensi), maka tujuan organisasi akan lebih mudah dicapai karena komunikasi dan hubungan antara karyawan dan pimpinan lebih baik. Hal ini juga akan membuat karyawan menemukan arti hakiki dari kenapa ia bekerja sehingga mereka akan merasa terpanggil dalam bekerja (calling).

Pimpinan sari anggrek menilai, cara yang tepat untuk menyalurkan visi kepada karyawan adalah dengan mengadakan kajian islam rutin setiap rabu pagi, sebelum aktivitas kerja dimulai. Selain itu untuk menjaga nilai transendensi yang ada pada karyawan, pimpinan mengadakan shalat berjamaah tepat waktu di mushalla toko dengan adzan dan iqamah yang langsung dikumandangkan oleh salah satu karyawan. Berbeda dari toko-toko lain yang biasanya hanya menyiarkan adzan dari radio atau televisi.

\subsection{Pengaruh Calling terhadap Komitmen Organisasional Karyawan}

Penelitian ini membuktikan bahwa calling berpengaruh signifikan positif terhadap komitmen. Rasa terpanggil untuk bekerja karena mengetahui arti/hakikat pekerjaan akan meningkatkan komitmen karyawan terhadap organisasinya. Merasa dihargai dan menjadi 
anggota keluarga organisasi membuat karyawan juga menjadi lebih komitmen terhadap organisasinya.

Rasa terpanggil yang ada pada karyawan yang disalurkan melalui kajian islam pekanan telah menanamkan nilai-nilai etika kepada karyawan. Sehingga dampak positif yang dimunculkan adalah ketenangan kerja pada diri karyawan. Selain itu, calling yang dimiliki karyawan membuatnya bekerja dengan jujur. Seperti yang diakui kepala unit, tujuan melakukan kajian pekanan adalah untuk menumbuhkan nilai kejujuran dalam diri karyawan. Jika tidak dilandasi dengan nilai transendensi, tentu mereka dapat saja berperilaku tidak jujur dalam pekerjaan mereka. Dengan adanya calling dan nilai transendensi, perilaku jujur dapat diciptakan dan ini semua adalah cerminan bagaimana karyawan berkomitmen terhadap pekerjaannya.

Penelitian ini memiliki hasil berbeda dengan hasil penelitian yang dilakukan oleh Fry dkk. (2005) yang menemukan nilai komitmen organisasional rendah pada tentara sebagai objek penelitian. Hasil positif (menguatkan komitmen) yang diperoleh dari penelitian ini dapat menjadi salah satu pendukung dari teori yang diajukan sebelumnya oleh Fry dkk. (2005), yaitu seseorang dengan perasaan calling dan membership akan merasa terpaut, setia, dan merasa untuk tetap berada di organisasi yang memiliki budaya sesuai nilai-nilai altruisme (lebih berkomitmen terhadap organisasi). Selain itu, penelitian dari Markow dan Klenke (2005) yang bertujuan untuk menginvestigasi efek calling terhadap komitmen organisasional pada teori spiritual leadership juga menemukan hasil bahwa calling berpengaruh terhadap komitmen organisasional.

\subsection{Pengaruh Altruisme terhadap Membership}

Nilai-nilai altruisme yang dimiliki oleh pemimpin akan mendasari pemimpin untuk mengadakan aktivitas-aktivitas yang akan mewujudkan rasa kekeluargaan, kasih sayang, dan merasa dihargai. Menurut Fry dkk. (2005) selain mewujudkan calling, tugas spiritual leader lainnya adalah membangun suatu budaya sosial/organisasi berdasarkan cinta altruistik dimana pemimpin dan pengikut sungguh-sungguh saling perhatian, peduli, dan menghargai satu sama lain, sehingga menghasilkan rasa keanggotaan, merasa difahami dan dihargai (membership). Di Toko Sari Anggrek, aktivitas-aktivitas ini berupa buka puasa bersama di rumah pimpinan selama bulan ramadhan. Ini menjadikan hubungan antara pimpinan dan karyawan menjadi lebih dekat, karena fasilitas yang dipakai di rumah pimpinan juga dipakai 
oleh karyawan. Hal ini menanamkan nilai keanggotaan yang begitu kuat pada karyawan. Ini juga menumbuhkan perasaan dihargai dan rasa menjadi bagian (member) pada karyawan.

\subsection{Pengaruh Membership terhadap Komitmen organisasional Karyawan}

Penelitian ini mengonfirmasi bahwa membership berpengaruh positif terhadap komitmen organisasional karyawan. Sebanyak 15\% dari karyawan sudah bekerja antara 1015 tahun di toko, bahkan sebesar 18,3\% karyawan sudah bekerja selama lebih dari 15 tahun di toko. Dari data kuesioner, ada karyawan yang sudah bekerja selama 35 tahun di toko. Ini menjadi bukti bahwa perasaan menjadi anggota dari toko dan merasa dihargai yang terus dibina oleh pimpinan dengan nilai altruisme yang dimiliki salah satunya dengan kegiatan buka bersama setiap hari di rumah pimpinan telah membuat karyawan menjadi loyal dan setia pada toko. Seperti hal yang sama yang diungkapkan Fry dkk. (2005) seseorang dengan perasaan membership akan merasa terpaut, setia, dan merasa untuk tetap berada di organisasi yang memiliki budaya sesuai nilai-nilai altruisme (lebih berkomitmen terhadap organisasi).

Namun hasil penelitian ini berbeda dengan hasil penelitian Fry dkk. (2005) yang mendapatkan hasil pengaruh membership rendah terhadap komitmen organisasional. Perbedaan ini diduga dikarenakan perbedaan desain organisasi objek penelitian. Fry dkk, (2005) menggunakan objek organisasi berdesain mekanistik, yaitu angkatan militer sementara penelitian ini menggunakan objek penelitian organisasi berdesain organik. Fry dkk. (2005) melporkan, setelah diwawancara, tentara menjelaskan, pemimpin tidak memimpin dengan contoh, lebih fokus pada kesalahan daripada penghargaan atas kerja keras, dan mengakui kurang waktu bersama keluarga. Perbedaan ini dapat memberi implikasi bagi pimpinanpimpinan bahwa untuk merealisasikan teori spiritual leadership pada organisasi, desain organisasi organik lebih mudah dan efektif daripada desain mekanik. Namun, hal ini tidak berarti desain organisasi mekanik tidak dapat menerapkan spiritual leadership. Organisasi mekanistik dapat menerapkan konsep spiritual leadership namun dengan usaha yang lebih ekstra dan dapat mengikuti beberapa arahan yang disarankan Fry dkk. (2005) pada implikasi penelitian.

\section{KESIMPULAN DAN IMPLIKASI}

Hasil penelitian menunjukkan bahwa pimipinan Toko Sari Anggrek yang merupakan spiritual leader ternyata dapat meningkatkan komitmen organisasional karyawan. Ini dibuktikan dengan adanya nilai signifikan dan positif pada semua hubungan pengaruh pada variabel-variabel yang ada pada model penelitian sehingga hasilnya dapat meningkatkan 
komitmen organisasional karyawan. Penelitian ini menguatkan teori spiritual leadership yang dikemukakan Fry (2003) dan mengonfirmasi kembali penelitian empiris yang yang dilakukaan Fry dkk. (2005) meskipun terdapat beberapa perbedaan hasil dikarenakan konteks penelitian berupa budaya organisasi dan desain organisasi termpat dilakukan penelitian juga berbeda.

Beberapa keterbatasan dari penelitian ini adalah, penelitian ini hanya menggunakan 60 sampel karena jumlah tersebut adalah jumlah seluruh karyawan toko. Penelitian selanjutnya diharapkan memiliki sampel yang lebih dari 100 sehingga dapat dengan lebih leluasa memilih alat analisis data yang lebih tepat untuk mengkonfirmasi sebuah teori. Kajian terhadap teori spiritual leadership ini masih tergolong kepada teori yang masih baru dan butuh banyak pengembangan dan pengujian lagi di berbagai sisi. Kemudian juga tidak terbatas kesempatan untuk menguji kembali model penelitian (Fry dkk., 2005) di masa yang akan datang, karena hasil yang diperoleh mengenai mekanisme pengaruh spiritual leadership terhadap komitmen organisasional ini masih belum konsisten.

\section{REFERENSI}

Allen, N. J., \& Meyer, J. P. (1990), “The measurement and antecedents of affective, continuance and normative commitment to the organization", Journal of Occupational Psuchology, Vol.63, No.1, pp. 1-18.

Asmaningrum, N. (2009), "Pengaruh Penerapan Spiriual Leadership Terhadap Komitmen Organisasi Pada Perawat di Rumah Sakit Islam Surabaya”, Thesis, Jakarta, Universitas Indonesia.

Fairholm, G. W. (1996), “Spiritual leadership : Fulfilling Whole Self need at work” Leadership $\mathcal{E}$ Organization Development Journal, Vol. 17, No.5, pp. 11-17.

Fry, L. W. (2003), “Toward a Theory of Spiritual Leadership", The Leadership Quarterly, Vol. 14, No. 6, pp. 693 - 727.

Fry, L. W. (2008), Spiritual leadership: state-of-the-art and future directions for theory, research, and practice. Spirituality in Business. New York: Palgrave Macmillan

Fry, L. W. Vitucci, \& Cedillo (2005), “Spiritual leadership and army transformation: Theory, measurement, and establishing a baseline" ,The Leadership Quarterly, Vol. 16, No. 5, pp. 835-862.

Fry, L. W., \& Cohen, M. P. (2009), “Spiritual Leadership as a Paradigm for Organizational Transformation and Recovery from Extended Work Hours Cultures", Journal of Business Ethics, Vol. 84, No. (2), pp. 265-278.

Fry, L.W. dan Matherly (2007), Spiritual leadership and organizational performance: an exploratory study. www.tarleton.edu.

Inkai, D., \& Anang K. (2013), “Pengaruh Spiritualitas di Tempat Kerja terhadap Turnover Intention melalui Komitmen organisasional", Iqtishoduna: Jurnal Ekonomi dan Bisnis Islam, Vol. 9, No. 1. 
Kaplan, R.S. \& Norton, D.P. (2004), Strategy Maps: Converting Intangible Assets Into Tangible Outcomes. Massachusetts, Boston: Harvard Business School Press.

Kertajaya, H. \& Sula, M. S. (2006), Syariah Marketing, Bandung, Penerbit Mizan.

Levy, R. (2000), "My Experience as Participant in the Course on Spirituality for Executive

Leadership", Journal of Management Inquiry, Vol. 9, No. 2, pp. 129-131.

Markow, F. \& Klenke, K. (2005), “The Effects of Personal Meaning and Calling on

Organisational Commitment: An Empirical Investigation of Spiritual Leadership", International Journal of Organizational Analysis, Vol. 13, No. 1, pp. 8-27.

Meyer, J. P. \& Allen, N. J. (1991), “A three-component model conceptualization of organizational commitment" Human Resource Management Review, Vol. 1, No. 1, pp. 6189.

Reave, L. (2005), "Spiritual Values and Practices related to Leadership Effectiveness", The Leadership Quarterly, Vol. 16, No. 5, pp. 655-687.

Tobroni (2010), The Spiritual Leadership, Malang, UMM Press. 